Tropical Journal of Pharmaceutical Research April 2012; 11 (2): 259-262

(C) Pharmacotherapy Group,

Faculty of Pharmacy, University of Benin, Benin City, 300001 Nigeria.

All rights reserved.

Research Article

http://dx.doi.org/10.4314/tjpr.v11i2.12

\title{
Isolation and Characterization of Lup-20(29)-ene-3, 28- diol (Betulin) from the Stem-Bark of Adenium obesum (Apocynaceae)
}

\author{
A Tijjani ${ }^{1 *}$, IG Ndukwe ${ }^{2}$ and RG Ayo ${ }^{3}$ \\ ${ }^{1}$ Ahmadu Bello University, School of Basic and Remedial Studies, Funtua, ${ }^{2}$ Department of Chemistry, Ahmadu Bello \\ University, Zaria, ${ }^{3}$ Division of Agric College, Samaru, Zaria, Nigeria
}

\begin{abstract}
Purpose: To isolate and characterize chemical compound(s) of biological importance from the stembark of the plant, Adenium obesum.

Methods: The stem-bark, after air-drying and powdering, was subjected to sequential hot-continuous extraction using petroleum spirit $\left(60-80^{\circ} \mathrm{C}\right)$ and methanol in that order. The petroleum spirit extract was chromatographed using thin layer and column chromatographic techniques. Recrystallization was used to further purify the isolated compound. Characterization of the isolated compound was by melting point, as well as by ${ }^{1} \mathrm{H}$ and ${ }^{13} \mathrm{C}$ nuclear magnetic resonance spectroscopy (NMR) and mass spectrometry (MS).

Results: A triterpenoid (lup-20(29)-ene-3, 28-diol), commonly known as betulin, was isolated from the crude petroleum ether extract of the plant stem-bark. The isolated compound's melting point was 256 $257{ }^{\circ} \mathrm{C}$. The name, betulin, was assigned to this compound by comparison of its spectroscopic data from ${ }^{1} \mathrm{H}-N M R,{ }^{13} \mathrm{C}-\mathrm{NMR}$ and $\mathrm{MS}$ analysis with those of authenticated samples reported in the literature. Conclusion: A known compound, betulin (lup-20(29)-ene-3, 28-diol) was isolated from the petroleum ether extract of the stem-bark of Adenium obesum.
\end{abstract}

Keywords: Adeniumobesum, Stem bark, Isolation, Iup-20(29)-ene-3,28-diol, Betulin 


\section{INTRODUCTION}

Adenium obesum (Apocynaceae) is a small deciduous succulent shrublet that can grow to shrub or small tree that belongs to plant family Apocynaceae [1]. The plant, which belongs to the genus Adenium, occurs in savanna, dry bushland or woodland and wooded grassland up to $2100 \mathrm{~m}$ altitude, on rocky or sandy soil [2]. It is used as poison on arrows [3] and also extensively for the treatment of a variety of ailments including venereal diseases; the root or bark extract is used as a bath or lotion to treat skin diseases and to kill lice, while the latex is applied to decaying teeth and septic wounds to promote healing and restoration. In Somalia, the root decoction, as nasal drops, is prescribed for rhinitis while in northern Kenya, the latex is rubbed on the head to kill lice and the powdered stem is applied on camels and cattle to kill skin parasites. The bark is also chewed as an abortifacient [4]. The ethanol extract of the root has been reported to slow down the growth of Bacillus subtilis, while not showing activity against Pseudomonas aeruginosa, Staphylococcus aureus and Candida albida. Extracts from the root have been shown to exert cytotoxic effect against several carcinoma cell lines $[5,6]$.

\section{EXPERIMENTAL}

\section{Plant material}

The stem-bark of Adenium obesum was collected from Samaru area of Zaria; Kaduna State, Nigeria. It was authenticated by Mr. Musa Mohammed of the herbarium of the Department of Biological Sciences, Ahmadu Bello University, Zaria, Nigeria, where a specimen (voucher number 1836) was deposited. The bark was air-dried and ground into powder using a porcelain, mortar and pestle. It was then sealed in a polyethene bag and stored in a dessicator prior to evaluation.

\section{Extraction}

The powdered stem-bark of Adenium obesum $(500 \mathrm{~g})$ was packed in a thimble, placed inside a soxhlet extractor and extracted exhaustively, first with petroleum spirit $\left(60-80{ }^{\circ} \mathrm{C}\right)$ for $48 \mathrm{~h}$ and then with methanol for $42 \mathrm{~h}$. The extracts were concentrated in vacuo at $40{ }^{\circ} \mathrm{C}$ in a rotary evaporator to yield the dry extracts.

\section{Isolation of compound}

Separation and purification of the various constituents of the crude extract were mainly done by column chromatography (CC) and recrystallization processes. Silica gel 60 (Fluka) was the adsorbent used for the chromatography. The solvent blend used was petroleum ether: ethyl acetate (EtOAC): chloroform in the ratio of 6:2:3. Qualitative thin layer chromatography (TLC) was used to monitor the column fractions and also to ascertain the purity of the isolate. TLC was run on aluminum and glass plates precoated with silica gel 60.F254 (Merck) with a thickness of $0.2 \mathrm{~mm}$ each. Visualization of spots on TLC was by Ultra Violet (UV) light and lodine vapour $[7,8]$. The melting point of the pure isolate was determined on a Gallenkemp melting point apparatus. Proton $\left({ }^{1} \mathrm{H}\right)$ and ${ }^{13} \mathrm{C}$ nuclear magnetic resonance (NMR) spectra were recorded on Jeol Eclipse spectrophotometer at a frequency of $500 \mathrm{MHz}$ for ${ }^{1} \mathrm{H}$ and $125 \mathrm{MHz}$ for ${ }^{13} \mathrm{C}$. These spectra were obtained on solutions of samples in deuterated chloroform $\left(\mathrm{CDCl}_{3}\right)$ with tetramethylsaline (TMS) as internal reference. Mass spectral (MS) were run on a HRFAB mass spectrometer.

\section{RESULTS}

The isolate was a white solid with a melting point of $256-257{ }^{\circ} \mathrm{C} .{ }^{13} \mathrm{C}$ NMR spectrum indicated a total number of thirty carbon atoms, and this number indicates triterpenoidal nucleus. The ${ }^{1} \mathrm{H} \quad \mathrm{NMR}$ spectrum six methyl groups at $\delta 1.67,0.99$, $0.97,0.96,0.80$ and $0.75 \mathrm{ppm}$, similar to the 
methyls attached to a triterpenoidal nucleus. The molecular ion peak ( $\mathrm{m} / \mathrm{z} 464.3645)$ also suggested a triterpenoid.

The results for the proton NMR (1H NMR), 13C NMR and mass spectrometry are presented below:

\section{Spectral data}

${ }^{1} \mathrm{H}$ NMR $(\mathrm{CDCl} 3,500 \mathrm{MHz}) \delta 4.70(1 \mathrm{H}, \mathrm{d}, \mathrm{H}-$ 29b), $4.58(1 \mathrm{H}, \mathrm{d}, \mathrm{H}-29 \mathrm{a}), 3.79(1 \mathrm{H}, \mathrm{d}, J=$ 10.8, H-28b), $3.33(1 \mathrm{H}, \mathrm{d}, J=10.8, \mathrm{H}-28 \mathrm{a})$, $3.18(1 \mathrm{H}, \mathrm{dd}, \mathrm{J}=5.3, \mathrm{H}-3 \alpha), 1.67(3 \mathrm{H}, \mathrm{s}, \mathrm{H}-$ 30), $0.99(3 \mathrm{H}, \mathrm{s}, \mathrm{H}-27), 0.97(3 \mathrm{H}, \mathrm{s}, \mathrm{H}-26)$, $0.96(3 \mathrm{H}, \mathrm{s}, \mathrm{H}-23), 0.80(3 \mathrm{H}, \mathrm{s}, \mathrm{H}-25), 0.75$ (3H, s, H-24).

${ }^{13} \mathrm{C}$ NMR (CDCl3, $\left.125 \mathrm{MHz}\right) \delta 150.6(\mathrm{C}-$ 20),109.8 (C-29), 79.2 (C-3), 60.6 (C-28), 55.4 (C-5), 50.5 (C-9), 48.8 (C-19), 47.9 (C17), 47.9 (C-18), 42.8 (C-14), 41.0 (C-8), 38.9 $(\mathrm{C}-1), \quad 38.8$ (C-4), $37.4 \quad(\mathrm{C}-10), 37.2$ (C13),34.3 (C-7), 34.1 (C-22), 29.8 (C-21), 29.2 (C-16), 28.1 (C-23), 27.5 (C-2), 27.1 (C15),25.3 (C-12), 20.9 (C-11), 19.2 (C-30), 18.4 (C-6), 16.2 (C-25), 16.1 (C-26), 15.4 (C24), 14.8 (C-27); HRFABMS m/z 464.3645

\section{DISCUSSION}

A doublet of doublets was present at $\delta 3.17$ ppm, which is characteristic of an $\alpha$-oriented hydrogen at C-3 of a $3 \beta$-hydroxy triterpene. Doublets for geminal protons at $\delta 4.70$ and $4.58 \mathrm{ppm}$, along with the methyl group at $\delta$ 1.67 ppm, suggests that 1 was a lupeol-type triterpene derivative. Another pair of doublets at $\delta 3.79$ and $3.33 \mathrm{ppm}$, rather than a seventh methyl singlet around $\delta 0.8$ ppm, confirms the presence of a second hydroxyl group at C-28. The ${ }^{13} \mathrm{C}$ NMR spectrum further established $\mathbf{1}$ as a lupeol-type triterpene derivative. The characteristic pair of $\mathrm{sp}^{2}$ carbons comprising the double bond of lupeol was observed as shifts at $\delta 150.6$ and 109.8 ppm [9]. Oxygenated carbon shifts for C-3 and C-28 were observed at $\delta 79.2$ and 60.6 ppm, respectively. In all, the spectra revealed a compound with six methyl groups, thirty carbon atoms (which is equivalent to the total number of carbon atoms in triterpenoid), a lupene-type triterpenoidal nucleus with two hydroxyl groups at C-3 and C-28 (a lupeoltype triterpene). Consequently, the compound was determined to be the known structure, 20(29)-lupene-3, 28-diol, more commonly known as betulin (Figure 1). Experimental NMR data was compared to that reported in the literature and all $13 \mathrm{C}$ shifts were within $\pm 0.3 \mathrm{ppm}[10,11]$.

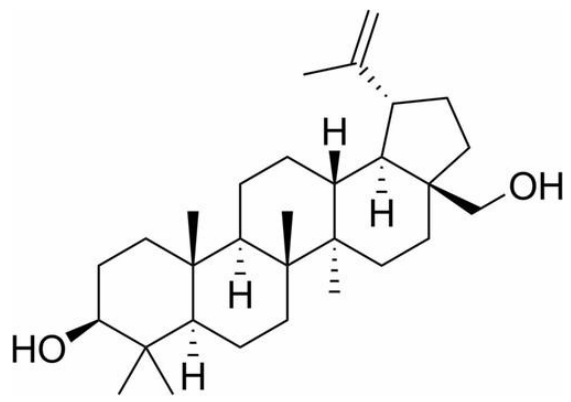

Fig 1: Structure of betulin

\section{CONCLUSION}

Based on the investigation conducted on the stem-bark of Adenium obesum, a triterpenoid compound, betulin was isolated, characterized and identified as lup-20(29)ene-3, 28-diol. This compound has been reported to exhibit anti-human immunodeficiency virus (anti-HIV), anticarcinogenic, anti-flu, anti-inflammatory, immune-omodulator, hepatoprotector, antihypoxic, anti-allergen, anti-tuberculosis, antitumor, anti-viral, aphidifuge, cytotoxic, hypolipemic, detoxicant (detoxicating agent), adaptogenic and anti-oxidant activities. It also prevents hyperlipidosis and acts as prostaglandin-synthesis and topoisomeraseII-inhibitor [12-15].

\section{REFERENCES}

1. Codd LE. Adenium obesum. The Flowering Plants of Africa. South African National Biodiversity Institute (SANBI), Pretoria, South Africa, 1987; 49: p 1953

2. Dimmitt MA, Hanson $C$. The genus Adenium in cultivation. Diplorhynchus Welw. ex Fic. \&

Trop J Pharm Res, April 2012;11 (2):261 
Hiern (Apocynaceae).Mededelingen, Cactus and Succulent. J., 1991; 63: 223-225

3. Watt JM, Breyer-brandwijk GM. The medicinal and Poisonous Plants of Southern and Eastern Africa, $2^{\text {nd }}$ Edition, E. \& S. Livingstone Ltd. Edinburgh and London, 1962; $p 941$

4. Neuwinger HD. African traditional medicine: a dictionary of plant use and applications. Medpharm Scientific, Stuttgart, Germany, 2000; $p 589$

5. Singh CU. Novel formulations of digitalis glycosides for treating cell-proliferative and other diseases. United States Patent Application 20040082521. U.S. Patent and Trademark Office, Alexandria VA, United States, 2004 [cited 2010 Mar 2]. Available from: www. freepatent.com

6. Graham JG, Quinn ML, Fabricant DS, Farnsworth NR. Plants used against cancer - an extension of the work of Jonathan Hartwell. J. Ethnopharm., 2000; 73: 347-377.

7. Stahl E, Kaltenbach PG. Antibody-dependent cellmediated cytotoxicity J. Chromatography, 1961; 5: 351-355

8. Steenkamp V, Mathivha E, Gouws MC, van Rensburg $C E$. Studies on antibacterial, antioxidant and fibroblast growth stimulation of wound healing remedies from South Afr J. Ethnopharmacol, 2004; 95(2-3): 353-357.

9. Reynolds WF, McLean S, Poplawski J, Enriquez RG, Escobar L, Leon I. Total Assignment of ${ }^{13} \mathrm{C}$ and ${ }^{1} \mathrm{H}$ Spectra of Three Isomeric Triterpenol Derivatives by

2DNMR: An Investigation of the Potential Utility of $1 \mathrm{H}$ Chemical Shifts in Structural

Investigations of Complex Natural Products. Tetrahedron, 1986; 42: 3419-3428.

10. Siddiqui $S$, Hafeez $F$, Begum S, Siddiqui $B$, Oleanderol S. A New Pentacyclic Triterpene from the Leaves of Nerium oleander. J. Nat. Prod., 1988; 51: 229-233.

11. Mahato $S B$, Kundu AP. ${ }^{13} C$ NMR Spectra of Pentacyclic Triterpenoids - A Compilation and Some Salient Features. Phytochemistry, 1994; 37: 1517-1575.

12. Biological properties of betulin [cited 2009 Dec 28]. Available from: http://www.betulin.ac/inform ation-about-bitulin.ht//

13. Perumal $Y$ and Dharmarajan S. Betulinic Acid and Its Derivatives: A Review on their Biological Properties.Curr Medicinal Chem, 2005;12:657666.

14. Abdel-Monem A, Kadriya SE, Rwaida AA and Jaber SM. Phytochemical and Pharmacological Studies of Maytenus forsskaoliana. Saudi Pharm J, 2003; 11 (4):184-191.

15.Robert HC and Samir AK. Chemistry, Biological Activity, and Chemotherapeutic Potential of Betulinic Acid for the Prevention and Treatment of Cancer and HIV Infection. Medicinal Res Rev, 2004; 24(1): 90-114 